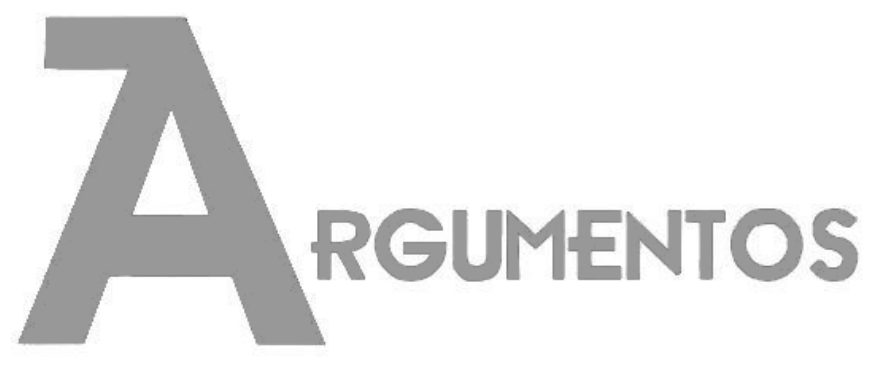

Vol. 17, n. 2, jul./dez. 2020 ISSN: 2527-2551 (online)

https://www.periodicos.unimontes.br/index.php/argumentos

\title{
Fernando de Azevedo e a cultura brasileira: relações possíveis ${ }^{1}$
}

\author{
Alessandra Santos Nascimento ${ }^{2}$
}

Recebido em: 10/01/2020

Aprovado em: 05/06/2020

Resumo: $O$ artigo versa sobre a contribuição do conceito de cultura brasileira de Fernando de Azevedo para a ideia de Brasil-nação no século XX, e para as teorias organizacionais. A interlocução com a obra deste autor se justifica por ser um intérprete oficial do conceito de cultura no país, desde a década de 1930, e também um significativo construtor institucional. A artesania intelectual aqui proposta contempla uma revisão bibliográfica que articula as produções de Azevedo e a literatura especializada sobre cultura brasileira e cultura organizacional. Como resultado, destaca-se que a noção de cultura legada por este autor permanece como uma referência importante para pensar o Brasil, possibilitando dentro e fora das organizações, a criação de um retrato multifacetado, provisório e flexível da sociedade brasileira. Ressalta-se ainda que, no século XXI, sua definição de cultura brasileira ainda orienta, implícita ou explicitamente, alguns teóricos que se dedicam a olhar para o contexto organizacional do Brasil, demonstrando como as culturas nacionais influenciam nos estilos administrativos.

Palavras-chave: Fernando de Azevedo. Cultura brasileira. Nação. Cultura Organizacional.

\section{Fernando de Azevedo y la cultura brasileira: posibles relaciones}

Resumen: El artículo aborda la contribución del concepto de cultura brasileña de Fernando de Azevedo a la idea de la nación brasileña en el siglo XX y a las teorías organizacionales. La interlocución con el trabajo de este autor se justifica por ser un intérprete oficial del concepto de cultura en el país desde la década de 1930 y también un importante constructor institucional. La artesanía intelectual propuesta aquí incluye una revisión bibliográfica que articula las producciones de Azevedo y la literatura especializada sobre cultura brasileña y cultura organizacional. Como resultado, se resalta que el concepto de cultura dejado por este autor sigue siendo una referencia importante para pensar Brasil al permitir, dentro y fuera de las

\footnotetext{
${ }^{1}$ Uma versão inicial deste texto foi apresentada como parte da monografia de especialização lato sensu de Governança Pública e Novos Arranjos de Gestão.

2 Doutora e mestre em Sociologia pela Universidade Estadual Paulista "Júlio de Mesquita Filho" (UNESP). É pesquisadora do Laboratório de Política e Governo da UNESP. Atualmente, colabora no Programa de Pós-Graduação em Desenvolvimento Territorial e Meio Ambiente da Universidade de Araraquara (UNIARA). Brasil. E-mail: alesantosnas@gmail.com. ORCID: https://orcid.org/0000-0002-6006-946X.
} 
organizaciones, la creación de un retrato multifacético, provisional y flexible de la sociedad brasileña. Además, se destaca que, en el siglo XXI, su definición de cultura brasileña aún guía, implícita o explícitamente, a algunos teóricos que se dedican a mirar a Brasil, demostrando cómo las culturas nacionales influyen en los estilos administrativos.

Palabras clave: Fernando de Azevedo. Cultura brasileña. Nacion. Cultura Organizacional.

\section{Fernando de Azevedo and the Brazilian culture: possible relations}

Abstract: The article relates the contribution of Fernando de Azevedo's concept of Brazilian culture to the idea of Brazil-nation in the 20th century and to organizational theories. The interlocution with the work of this author is justified by being an official interpreter of the concept of culture in the country since the 1930s and also an important institutional builder. The intellectual craftmanship proposed here includes a bibliographic review that associates Azevedo's productions and specialized literature on Brazilian culture and organizational culture. As a result, it is highlighted that the concept of culture left by this author continues to be an important reference for thinking about Brazil, allowing, within and outside organizations, the creation of a multifaceted, passing and flexible portrait of Brazilian society. In addition, it is noted that, in the 21st century, its definition of Brazilian culture still guides, implicitly or explicitly, some theorists who are dedicated to looking at Brazil, demonstrating how national cultures influence administrative styles.

Keywords: Fernando de Azevedo. Brazilian Culture. Nation. Organization Cultural.

\section{A cultura brasileira e os discursos sobre a nação}

As ideias que orientaram a definição de cultura brasileira na obra de Fernando de Azevedo 3 estiveram subjacentes em suas incursões como gestor público, seja no Rio Janeiro (onde foi diretor-geral da Instrução Pública do Distrito Federal, nos anos de 1927 a 1930), seja em São Paulo (como diretor-geral da Instrução Pública do Estado de São Paulo em 1933). Contudo, elas encontraram no Instituto Brasileiro de Geografia e Estatística (IBGE) um lócus privilegiado para sua sistematização e difusão. Primeiro, por este intelectual exercer o cargo de consultor técnico ${ }^{4}$ na temática de cultura, ao longo

\footnotetext{
${ }^{3}$ Fernando de Azevedo (1894-1974), mineiro de São Gonçalo do Sapucaí, foi educado em colégios jesuítas, período em que teve seu espírito esculpido pelas literaturas e letras clássicas (latim e grego). Formou-se em Ciências Jurídicas, em 1918, pela Faculdade de Direito do Largo de São Francisco em São Paulo. Ele foi, ao longo de sua trajetória intelectual, um autodidata e, assim, tornou-se sociólogo e educador. A partir de 1931, no interior da Cia. Editora Nacional, editou importantes obras científicas e literárias no, para e sobre o Brasil. Foi na referida instituição que ele criou e dirigiu a Biblioteca Pedagógica Brasileira (BPB) assim como suas coleções: Brasiliana, Atualidades Pedagógicas e Iniciação Científica (DUTRA, 2006). Ao colaborar para a criação de novos públicos, e também conformar suas percepções, gostos, interesses, ideias etc., pode-se sugerir que sua trajetória editorial foi um dos caminhos a partir do qual Azevedo agiu diretamente sobre a cultura brasileira, contribuindo em sua modelagem ao selecionar, promover e/ou silenciar determinadas interpretações sobre a nação (TOLEDO, 1995). Para um aprofundamento dessas questões consultar as obras de Nascimento $(2018,2012)$.

${ }^{4}$ Os consultores técnicos foram colaboradores do IBGE selecionados pelos dirigentes deste Instituto de acordo com a seguinte consideração: "[...] deverão ser cidadãos de notável cultura e de reconhecida
} 
das décadas de 1940 e 1950, o que Ihe possibilitou influência e legitimidade. Segundo, pelo fato de o governo demandar, no contexto do primeiro recenseamento nacional do IBGE, nos anos de 1940, uma interpretação a respeito do Brasil-nação que pudesse se tornar hegemônica dentro e fora do país.

Azevedo atuou como articulador de um vasto repertório conceitual que estabeleceu a expressão "cultura brasileira" como um suporte para responder a esta demanda por uma identidade nacional. Nesse sentido, ele sistematizou diferentes discursos em seu livro intitulado $A$ cultura brasileira ${ }^{5}$, que contou com o patrocínio do governo de Vargas em sua fase ditatorial. Sobre este fato, é válido ressaltar que apesar desta obra ter sido publicada sob a égide do Estado Novo isto não representou uma adesão a este por parte de seu autor (TOLEDO, 1995).

A “cultura brasileira", expressão genérica e título do livro de Azevedo (1971), se tornou responsável por explorar as convergências entre os diferentes discursos vigentes no país, sem desconsiderar suas divergências teórico-metodológicas. Dentre tais discursos destacaram-se: 1) o funcionalista, influenciado pelas obras de Émile Durkheim e Bronislaw Malinowisk; 2) o racialista, baseado nos estudos de Silvio Romero e Oliveira Vianna, dentre outros, e 3) o culturalista, pautado, principalmente, nas reflexões de Franz Boas ${ }^{6}$ e Gilberto Freyre (TOLEDO, 1995).

Para Azevedo (1971), esse repertório foi sendo elaborado em momentos históricos distintos, mas sempre com a mesma preocupação, a saber: dar respostas aos obstáculos que impediam o Brasil de se tornar uma nação moderna, coesa e harmônica, especialmente, a partir dos anos de $1920^{7}$. Ainda segundo este autor, esses discursos se complementavam na explicação e na busca de soluções para o país. Desta forma, não se tratava de ignorar as arestas e as contradições teórico-metodológicas existentes na produção nacional e internacional, mas de propor uma interpretação a respeito do Brasil que fosse capaz de explicar seu passado, entender seu presente e projetar seu futuro.

especialização na seção técnica que Ihes for atribuída" (REVISTA DE ECONOMIA E ESTATÍSTICA, 1937, p. 59).

${ }^{5}$ Este livro foi publicado pela primeira vez em 1943, contudo, neste artigo é utilizada a edição de 1971.

${ }^{6}$ Reflexões que foram apresentadas nos livros: Anthropology and modern life, de 1929; Changes in bodily form of descendants of immigrants (1910-1911) e The mind of primitive man, de 1911.

7 Um período marcado, no contexto interno, pelo centenário da independência e pela Semana de Arte Moderna. E, no contexto externo, pela experiência desastrosa da Primeira Guerra Mundial que recolocou o tema da nação. 
Tendo isso em conta, Azevedo buscou estabelecer um diálogo criativo e pertinente entre as diferentes teorias e metodologias.

Semelhante abordagem também era familiar a intelectuais como Gilberto Freyre $^{8}$, cujas análises sobre o Brasil demonstravam um raciocínio avesso ao reconhecimento das contradições, das desigualdades, dos embates etc. como algo habitual. Este tipo de visão parece ter colaborado para que tais autores fossem denominados como ensaístas ${ }^{9}$, isto é, vistos como intérpretes que transitavam nos campos científico e literário, construindo um conhecimento aberto mesmo diante de temas como o da cultura brasileira e o da identidade nacional.

Dentre as políticas públicas consideradas importantes para efetivar a modernização do Brasil se destacaram as de educação, saúde, trabalho e imigração. Elas foram influenciadas pelas interpretações sobre a identidade nacional à medida que esta colaborou para caracterizar o público a ser atendido. Nesse contexto, torna-se relevante conhecer as ideias que foram mobilizadas para a definição da identidade nacional, principalmente, ao entendermos que sua escolha e uso pretendiam satisfazer a um projeto de nação moderna e harmônica.

Grosso modo, podemos destacar na definição de identidade nacional a presença de pelo menos dois conceitos: raça e cultura. Cada um deles, apesar de ser expressão de um tipo diferente de discurso (racialista ou culturalista), não representava necessariamente sua superação. Um exemplo disso foi o fato dos avanços conceituais presentes no campo da Biologia com Darwin (evolução) e Mendel (mutação), já no final do século XIX, e da Antropologia com Franz Boas, no início do século XX, só terem sido incorporados por uma minoria dos teóricos brasileiros e/ou estrangeiros para pensar a identidade nacional.

A recusa por parte da intelectualidade brasileira em abarcar esses avanços possibilitou duas consequências. A primeira, a permanência dos termos raça e meio no quadro interpretativo do Brasil como categorias do conhecimento até meados do século

\footnotetext{
${ }^{8}$ A principal obra de Gilberto Freyre mobilizada para as reflexões sobre o tema foi Casa grande e senzala, publicada originalmente em 1933, no presente artigo utilizamos a edição de 2000.

${ }^{9} \mathrm{O}$ termo ensaísta não apresenta nenhuma conotação pejorativa neste artigo. Contudo, vale destacar que ele foi mobilizado com este sentido por alguns intelectuais, a partir da década de 1950, com o intuito de desqualificar parte dos intérpretes do Brasil que se distanciava, em virtude de suas filiações teóricas e metodológicas, do arcabouço marxista.
} 
XX. Inclusive, concorrendo com a lição deixada por Boas: de que não há culturas superiores ou inferiores, sendo todas elas fenômenos específicos e originais (ORTIZ, 2003). A segunda, a ressignificação dos conceitos de raça e cultura. Ambos foram reelaborados com o objetivo de satisfazerem à construção de uma identidade nacional mestiça e coesa. Um expoente desta ressignificação no país foi Freyre $(2000)^{10}$, em sua obra Casa grande e senzala. Nesta, o conceito de raça teve sua dimensão de dinamismo negligenciada, enquanto o de cultura apresentou-se de forma ambígua, ora próxima às concepções de Franz Boas, ora permeada por determinismos biológico e geográfico.

Outros subsídios para a definição do conceito de identidade nacional podem ser encontrados nas observações de Azevedo (1971) acerca do padrão harmônico das relações étnico-raciais no Brasil. Tais apontamentos apoiaram-se, particularmente, na compreensão ambígua de cultura legada por Freyre (2000), e objetivaram a definição de uma ideia genérica de povo, marcada pelas noções de interpenetração e reconhecimento da diversidade no país.

Guardando as devidas proporções, é possível afirmar que a noção de cultura brasileira, compartilhada por Freyre (2000) e Azevedo (1971), expressou com sucesso um projeto intelectual e político de monopólio oficial das ideias sobre a brasilidade para dentro e para fora do país. No entanto, contrariamente à análise de Mota $(2002)^{11}$, que classifica Azevedo como um ideólogo da cultura brasileira ${ }^{12}$, corroboramos a de Toledo (1995). Para esta estudiosa, a “[...] interpretação de Azevedo é legitimada pelo lugar onde é produzida, pelo método científico adotado e pela sua própria participação e testemunho da 'história mais recente'”' (TOLEDO, 1995, p. 95, aspas da autora).

Independentemente da postura de Freyre (2000), em filiar seu conceito de cultura à influência teórico-metodológica de Franz Boas, ele também foi considerado por Mota (2002) como um ideólogo da cultura brasileira. De acordo com este autor, semelhante vinculação representou, à época, uma estratégia de Freyre para se autoafirmar enquanto um intérprete moderno no contexto interno e externo.

\footnotetext{
${ }^{10}$ Lembrando que a primeira edição de Casa grande e senzala ocorreu em 1933.

${ }^{11}$ A obra de Mota (2002) teve sua primeira edição em 1977.

12 Por ideólogo da cultura brasileira entende-se, grosso modo, a partir da obra de Mota (2002), um intelectual comprometido com o falseamento da realidade do país.
} 
Já o fato do conceito de cultura de Freyre (2000) pouco se diferenciar daquelas definições presentes no país, desde o século XIX, não deve obscurecer sua importância, a qual consiste na valorização discursiva da mistura. No entanto, é preciso explicitar o limite da interpretação freyreana que considera a concepção de interpenetração como sincretismo (NASCIMENTO, 2005). Para esta autora, para que fosse possível falar em sincretismo no Brasil, os grupos envolvidos na mistura (negros, indígenas, brancos) teriam que ser equivalentes enquanto "lugares" diferenciados no processo de troca simbólica, mas esta condição nunca foi satisfeita no país. O sincretismo foi apenas retórico e funcionou como um “[...] biombo 'harmônico-pluralista' para esconder a realidade da discriminação" (SODRÉ, 1988, p. 132, aspas do autor).

Desse modo, a concepção hierárquica e a visão determinista sobre os diferentes grupos sociais expressaram outro limite importante da abordagem freyreana. Tal limitação possibilitou a ocorrência de dois processos: o de culturalização do conceito de raça e o de racialização do conceito de cultura, os quais foram amplamente difundidos nas e pelas obras de Freyre (2000) e de Azevedo (1971).

A noção de cultura brasileira, e a ideia genérica de povo que a mesma alicerçava, foram mobilizadas, até a década de 1950, como estratégias para obscurecer o quadro de desigualdade étnico-racial do Brasil. Ou seja, para ofuscar a fragilidade e, de certa forma, a arbitrariedade de uma elaboração identitária que aceitou a diversidade apenas retoricamente (NASCIMENTO, 2005). Assim, as interpretações de Freyre (2000), sobre o padrão idílico das relações étnico-raciais no país, instituíram uma visão harmônica e mestiça da identidade nacional na conjuntura dos recenseamentos efetivados pelo IBGE, a partir dos anos de 1940.

No texto de Mortara ${ }^{13}$, que foi publicado no contexto do primeiro recenseamento nacional, é possível acompanhar a natureza dessa representação sobre o país:

[...] os descendentes das mais diversas estirpes confraternizam numa atmosfera de liberdade e de igualdade, e pela comunhão no trabalho e pelos

\footnotetext{
${ }^{13}$ Estatístico de origem italiana que chegou ao Brasil no ano de 1939. Veio ao país a convite do governo brasileiro para atuar no primeiro recenseamento nacional em 1940. Mortara possibilitou a utilização, pela primeira vez no Brasil, dos quesitos que permitiram o levantamento de dados confiáveis sobre fecundidade e mortalidade.
} 
conúbios fecundos, fundem-se num só povo, apagando ódios milenários e reconstituindo numa nação nova a primitiva unidade dos filhos de Adão. [...] A diversidade das origens étnicas não atenua nos brasileiros a intensidade do sentimento nacional, antes the confere um caráter particular de solidariedade humana na elevação dos ideais comuns (MORTARA, 1940, p. 431).

Foi a difusão desse cenário de harmonia étnico-racial descrito e reiterado pelos teóricos ibgeanos (como Azevedo, Freyre e Mortara para citarmos apenas três exemplos), nos âmbitos interno e externo, que possibilitou ao Brasil ser considerado um exemplo de respeito à diversidade durante e após a Segunda Guerra Mundial. Este retrato aprazível do país influenciou em sua escolha pela Organização das Nações Unidas para a Educação, a Ciência e a Cultura (UNESCO) para sediar uma série de pesquisas sobre as relações raciais. O interesse da UNESCO pelo Brasil parece só ter sido confirmado em razão desta instituição ter encontrando aqui uma tradição já constituída de estudos raciais. De qualquer forma, o fato é que as pesquisas financiadas pela UNESCO não conseguiram descobrir o segredo da propagada harmonia racial, porém permitiram lançar luz sobre os dados do recenseamento de 1940, confirmando que a desigualdade social no país tinha cor.

No Brasil, a década de 1950 foi marcada por um intenso processo de disputa por financiamentos para os estudos acadêmicos e também pela legitimidade de suas explicações no interior das e entre as instituições voltadas ao ensino, à cultura e à pesquisa. Por outro lado, este período também registrou um aumento das demandas governamentais por propostas que assegurassem o desenvolvimento do país. Tendo em vista que essa década se caracterizou pelo reconhecimento do subdesenvolvimento como uma condição estrutural de alguns países dentro do sistema capitalista mundial. Os apontamentos fomentados pelas abordagens marxistas adquiriram relevância heurística para entender o Brasil e, simultaneamente, colocaram o conceito de classes sociais no centro dos debates.

As transformações ocorridas nas categorias explicativas da realidade social brasileira, em virtude da preponderância do discurso marxista, principalmente a partir dos anos de 1960, colocaram em xeque as reflexões sobre a cultura brasileira e a identidade nacional, classificando-as como ideológicas. Isto é, como falseadoras da 
realidade do país. O livro de Mota (2002), já citado, expressou este tipo de avaliação, ao afirmar em suas conclusões que, no plano teórico

[...] atingiu-se a formulação clara segundo a qual a Cultura Brasileira existe apenas para seus ideólogos. [No plano político,] [...] a ideologia da Cultura Brasileira funcionou como elemento de integração [...] dissolvendo [...] as contradições que poderiam alterar as condições do controle social em vigência [...]. [Já no plano conceitual as] noções ideológicas [teriam excluído as] [...] categorias de análise, que auxiliariam na instauração de um possível discurso científico (MOTA, 2002, p. 283-284). (Destaque do autor).

No entanto, esta crítica de Mota (2002) precisa ser vista com cautela devido a um conjunto de razões, do qual destacaremos duas. Primeira, se em um dado momento este autor afirma que a "[...] Cultura Brasileira existe apenas para seus ideólogos", como aparece no trecho acima. Em outra passagem, ele se posiciona como um desses ideólogos ao fazer uso dessa expressão atestando sua existência ${ }^{14}$. Segunda, é necessário considerar Mota (2002) como um ator social, ou seja, como alguém que falava de um determinado lugar. No caso em questão, a partir da tradição marxista. Como outros expoentes desta tradição no Brasil, Mota (2002) estava preocupado, principalmente após o golpe de 1964, em colaborar para estabelecer no país a hegemonia das explicações "críticas". Desse modo, encontrava-se em clara concorrência com os intelectuais de formação e filiação teórica distintas das suas, a exemplo de Freyre e de Azevedo.

Ao empregar sua definição de cultura brasileira, para refletir acerca das relações entre a cidade e o campo nos anos de 1950, Azevedo (1962) estabeleceu o sentido de aculturação, o qual nos sugere indícios a respeito de como os diferentes grupos sociais reagem frente às mudanças. Para este autor, por aculturação era possível entender a transformação na cultura material ou imaterial de dois ou mais grupos humanos em relações de contato. Considerando o processo de colonização no Brasil e a política de imigração no final do século XIX, e no início do século XX, podemos apontar que o país representava um grande laboratório para esse tipo de estudo. $\mathrm{O}$ aspecto mais interessante da acepção de aculturação formulada por esse autor era a ideia de que a

\footnotetext{
14 O referido uso encontra-se nas páginas 289-290 do seu livro.
} 
condição do progresso dos grupos sociais encontrava-se, ao mesmo tempo, no contato e na diferenciação entre as culturas ${ }^{15}$, o que favorecia a noção de respeito à diversidade.

Todavia, é indispensável ponderar que o respeito à diversidade tinha um limite claro: não podia ameaçar a unidade nacional. Sendo assim, Azevedo não hesitou, na conjuntura do Estado Novo, em apoiar a ação truculenta do governo de Vargas de encerrar o funcionamento de inúmeras escolas "étnicas". Isto é, de fechar as organizações educacionais que pertenciam aos imigrantes e, em seu lugar, fundar escolas "nacionais", as quais tinham a obrigação de garantir o ensino da língua portuguesa (LESSER, 2001). Na visão de Azevedo, este procedimento fortalecia a identidade nacional e a cultura brasileira e, desse modo, assegurava a coesão nacional.

Ao definir a cultura como um todo estruturado, que comporta várias esferas intimamente ligadas, Azevedo (1962) procura esclarecer que a mudança ocorrida em uma delas não se realiza de forma simultânea nas outras. Isto implica em apontar que entre uma esfera e outra pode ocorrer o fenômeno da "demora cultural", que consiste em uma diferença no seu ritmo de desenvolvimento. Ao analisar o funcionamento da esfera material e imaterial da cultura, esse autor pondera que pode haver uma diferença de atitude em face das categorias de ideias tecnológicas e não-tecnológicas. Desta forma, enquanto as ideias tecnológicas seriam absorvidas com maior rapidez pelos indivíduos, as não-tecnológicas sofreriam resistências. Estas reflexões são importantes, pois nos auxiliam a compreender a reação dos indivíduos no interior das organizações. Nestas, o primeiro tipo de ideia é absorvido e reproduzido sem grandes questionamentos, desde que seja reconhecida sua eficácia e eficiência. Enquanto o segundo tipo encontra inúmeros obstáculos para ser incorporado, porque se relaciona com a personalidade, a história de vida, os sonhos, as vontades, enfim, com uma dimensão mais profunda dos indivíduos.

Para Azevedo (1962), é na relação entre o "indivíduo" e o "social" que a personalidade e a cultura promovem o duplo fenômeno de assimilação e diferenciação que se encontra na base das mudanças sociais. Desse modo, refletir sobre os fatores que intervém neste duplo fenômeno pode contribuir para a elaboração de estratégias que busquem vencer as resistências culturais em face das mudanças. Estas ideias nos

\footnotetext{
15 Para realizar semelhante afirmação, Azevedo apoiou-se em Lévi-Strauss. A referência bibliográfica em questão é Race et Histoire, obra publicada em 1952.
} 
asseguram algumas pistas para nos aproximarmos do tema da mudança nas organizações. Já abordar este tema nos coloca o desafio de entender como se constrói a unidade na sociedade e, deste modo, a sua continuação.

Para tentar responder a este desafio torna-se imperioso trabalhar as relações entre os conceitos de educação e cultura. Azevedo $(1971,1962)$ discorre acerca de tais relações, destacando que a educação consiste em um mecanismo de perpetuação das culturas, pois transmite a herança social de uma geração à outra, e que ela é parte constitutiva da cultura. Para argumentar nesses termos, ele se apoia nas contribuições de Émile Durkheim. Já ao ponderar sobre o mecanismo de "transmissão", ressalta que a cultura não seria "recebida" e sim "reconstruída" pelas novas gerações. Nesse caminho, expõe que as diferenças cognitivas, motoras, culturais etc. entre as gerações jovens e as maduras interviriam para dificultar a "recepção" daquelas. Ou seja, atuariam potencialmente como "agentes" da "reconstrução" cultural. Para embasar tal análise, Azevedo (1962) recorre aos escritos de John Dewey.

As reflexões realizadas ao longo deste tópico do presente artigo podem ser resumidas da seguinte forma: 1) a concepção de cultura brasileira de Fernando de Azevedo $(1971,1962)$ foi consideravelmente influenciada pela obra de Freyre (2000); 2) tal definição de cultura funcionou como uma resposta à demanda do governo por uma identidade nacional, nas décadas de 1930 e 1940; 3) a trajetória de Azevedo como intelectual e homem público o influenciou a fazer dialogar, teoricamente e na prática, o que parecia paradoxal aos olhos de outros intérpretes, e 4) sua noção de cultura brasileira ainda permanece, no século XXI, como uma referência importante para pensar o país, ao comportar uma dimensão positiva e dinâmica que lhe permite criar um retrato multifacetado, provisório e flexível da sociedade brasileira.

\section{Cultura brasileira e cultura organizacional}

O conceito de cultura brasileira de Fernando de Azevedo (1971) compreende a noção de que cada sociedade, em distintos períodos históricos, é capaz de desenvolver uma síntese dos diferentes e concorrentes valores, ideias, aspirações, gostos, interesses etc. dos grupos que a compõem. Tal síntese pode ou não se institucionalizar, com maior ou menor sucesso, por um tempo conjunturalmente determinado. Essa acepção do 
conceito de cultura brasileira não tem um conteúdo específico, ou seja, não comporta nenhuma essência atemporal, porém é apropriada para representar em um dado momento, de uma formação social determinada, o coletivo na diversidade. Diante desses apontamentos, é possível sugerir que o significado que Azevedo atribui a tal conceito não apresenta incompatibilidade com a afirmação de Bosi (1999), segundo a qual

[...] não existe uma cultura brasileira homogênea, matriz dos nossos comportamentos e dos nossos discursos. Ao contrário: a admissão de seu caráter plural é um passo decisivo para compreendê-la como um "efeito de sentido", resultado de um processo de múltiplas interações e oposições no tempo e no espaço (BOSI, 1999, p. 7). (Itálico e aspas do autor).

Desse modo, ambas as definições de cultura brasileira parecem férteis para ser relacionadas com as teorias organizacionais, na medida em que nos possibilitam diretrizes para explicarmos os comportamentos dos funcionários e dos executivos no interior das organizações. Tais comportamentos são baseados e motivados por crenças, valores, sentimentos, interesses etc. que se encontram disseminados na cultura nacional de uma dada sociedade, no caso do Brasil, difundidos na cultura brasileira.

Destarte, é a cultura que possibilita um referencial que permite aos atores sociais atribuírem um sentido ao mundo e a sua própria existência. A "[...] cultura é um contexto, onde os acontecimentos sociais, as ações, as instituições ou os processos podem ser descritos de forma inteligível e com densidade" (GEERTZ, 1989, p. 8).

As organizações, ao fazerem parte da sociedade, são expressões de sua cultura e produtoras de subculturas, isto é, de culturas específicas. Neste sentido, ao reconhecerem a cultura nacional como um dos fatores na formação da cultura organizacional, alguns estudiosos têm ponderado que "[...] cada organização delimita uma cultura organizacional única, gerada e sustentada pelos mais diversos elementos e formas" (FREITAS, 1997, p. 41). A aproximação entre os conceitos de cultura organizacional e de cultura nacional (brasileira) decorre do fato de que grande parte do referencial teórico-metodológico das investigações sobre a cultura organizacional tomou de empréstimo reflexões e conceitos presentes nos campos da Etnologia, da Antropologia e da Sociologia. 
Para Azevedo (1971), é através da cultura que se pode reconhecer, na diversidade que caracteriza o Brasil, as conexões que formaram e formam a mentalidade da população. Ou seja, o coletivo na diversidade dos grupos sociais. A cultura seria responsável por manter a unidade da sociedade ao longo do tempo, tendo em conta que ela é transmitida pela educação. Esta última, apesar de ser o lócus de difusão das tradições, não deixa de ser também um produto cultural. De acordo com Toledo (1995), tal definição de educação permite torná-la um critério daquilo que é essencial em uma sociedade, pois é a partir dela que a sociedade comunica o que é fundamental para manter-se coesa.

Ainda segundo esta autora, cuja inspiração é a obra de Azevedo (1971), só existe "[...] a possibilidade de estudar a mudança em uma determinada sociedade se houver uma "unidade" capaz de Ihe explicar a continuidade" (TOLEDO, 1995, p. 120, aspas da autora). Esta unidade deve ser buscada "[...] 'no sistema de valores incorporado a este grupo'" (TOLEDO, 1995, p. 120; itálico e aspas da autora), isto é, deve ser procurada na cultura. Para Azevedo, na visão de Toledo (1995) e na nossa, é a cultura que expressa o que dá significado e unidade ao organismo social.

Considerando que é a cultura que proporciona sentido e coesão à sociedade, Motta (1997) recorre a um conjunto de estudos a respeito dos comportamentos de funcionários e empresários, de diferentes países do mundo, para demonstrar como as culturas nacionais influenciam nos estilos administrativos. Neste caminho, procura refletir sobre a cultura e as organizações no Brasil, dando destaque à existência de uma distribuição desigual de poder entre tais atores (MOTTA, 1997, p. 28). O alto índice de distância de poder no país pode ser entendido ao levarmos em conta seu passado patrimonialista, escravocrata e patriarcal. Isto é, ao considerarmos os aspectos da cultura nacional resultante e, concomitantemente, ressignificadora da formação social brasileira.

Uma avaliação semelhante a respeito do índice de distância de poder no Brasil, e suas causas, foi desenvolvida no texto de Wood Jr. (1997). Para este autor, tal distância pode ser compreendida pelo fato de a "[...] estrutura social escravocrata ainda [ser] [...] o modelo cognitivo de referência de parte apreciável dos atores sociais no país" (WOOD JR., 1997, p. 153). 
Apoiando-se no estudo de DaMatta (1983), Motta (1997) explica que no âmbito das organizações brasileiras, apesar da existência de uma elevada distância de poder, ocorre algo que não pode ser caracterizado como “[...] democracia, mas também não é autocracia. Trata-se de algo intermediário, ambíguo, como muitos traços da cultura brasileira" (MOTTA, 1997, p. 33). Esta reflexão sobre a ambiguidade de alguns traços da cultura é resgatada e aprofundada pela pesquisa de Freitas (1997). De acordo com este intelectual, os traços culturais consistiriam em um conjunto de características que seriam frequentes, porém passíveis de serem ressignificadas para a maioria dos atores sociais do país. Desta maneira, os traços compreenderiam parte do inconsciente de cada indivíduo e seriam mobilizados para que este pudesse enxergar a si próprio como brasileiro.

$\mathrm{Na}$ busca por entender os referidos traços, Freitas (1997) estabelece uma análise sobre a cultura brasileira tendo como principais interlocutores Azevedo (1971) e Bosi (1999) ${ }^{16}$. No trabalho deste último, Freitas (1997) encontra a definição de cultura que procura explorar intensamente, a saber: "plural sim, mas não caótica". Desse modo, para este autor, a cultura brasileira compreende um mapa de subculturas alicerçado sobre a divisão social do país.

Destaca-se como uma das principais contribuições de Freitas (1997), para pensar a relação entre a cultura brasileira e a cultura organizacional, ter sumarizado os traços culturais que seriam influentes nas organizações brasileiras. Dentre tais traços podemos observar: 1) a hierarquia, cujas principais características seriam: a tendência à centralização do poder e ao distanciamento nas relações entre os diferentes grupos sociais assim como a passividade e a aceitação de grupos inferiores ${ }^{17} ; 2$ ) o personalismo, ou seja, relações sociais baseadas nas relações pessoais e no domínio moral e econômico (paternalismo); 3) a malandragem: flexibilidade e adaptabilidade como estratégias de sobrevivência (jeitinho); 4) o sensualismo e 5) o aventureiro, isto é, um traço que expressa a tendência de aversão ao trabalho manual e/ou metódico ${ }^{18}$.

\footnotetext{
${ }^{16}$ Freitas utilizou em seu artigo outra edição desta obra de Bosi (1999), ou seja, a publicação do ano de 1987.

17 Este traço apareceu na análise de Motta (1997) mencionada anteriormente em outro registro: a distância de poder.

18 Não nos deteremos na elaboração de uma interpretação envolvendo o surgimento, desenvolvimento e/ou as consequências dos traços gerais da cultura brasileira. Contudo, vale mencionar alguns trabalhos que contribuíram, direta ou indiretamente, para este tipo de abordagem: Azevedo (1971), Freyre (2000),
} 
Para exemplificarmos como um destes traços culturais pode ser percebido nas organizações, selecionamos o personalismo. Segundo este, ao olharmos para uma organização (a exemplo de uma empresa), o chefe (isto é, o "empregador") seria capaz de exercer o controle sobre seu funcionário (ou seja, o "empregado") e de impor a este suas ordens; e, ao mesmo tempo, de colaborar para a realização de algo de interesse deste. Por sua vez, o funcionário, ao sentir-se protegido e/ou favorecido pelo chefe, poderia Ihe retribuir com sua lealdade, configurando, deste modo, o estabelecimento de uma relação paternalista no cotidiano organizacional.

A pesquisa desenvolvida por Barros e Prates (1997) complementou a de Freitas (1997) ao ter acrescentado novos traços nacionais (formalismo, impunidade, flexibilidade etc.) aos sugeridos por ele, e também ao ter identificado uma combinação entre os traços para explicar o que é o estilo brasileiro de administrar. Ao realizarem entrevistas com um grupo considerável de executivos e de dirigentes no Brasil, Barros e Prates (1997) concluíram que a maioria dos entrevistados reconhecia a coexistência dos traços de formalismo e de flexibilidade nas empresas, independentemente disso parecer paradoxal. Com isso, estes autores sugeriram que a forma de existir e conviver com os paradoxos e com as ambiguidades da cultura brasileira nas organizações consistiria na "arte brasileira de administrar". Estas ideias corroboraram e aprofundaram a interpretação de Motta (1997) de que as culturas nacionais influenciam nos estilos administrativos dos países ${ }^{19}$.

Vale a ressalva que, devido ao fato da maioria dos estudos sobre cultura organizacional ter sido realizada em um tipo específico de organização, ou seja, nas empresas, a extensão de suas conclusões para os outros tipos de organização (universidades, sindicatos, partidos políticos, igrejas, ONGs etc.) pode ficar parcialmente comprometida (BARBOSA, 2002). No entanto, a validade de tais conclusões é assegurada pelo fato de todas as organizações serem influenciadas pela cultura nacional, no caso em questão, pela cultura brasileira.

Holanda (1989), Ortiz (2003), Mota (2002), Bosi (1999), DaMatta (1986, 1985, 1983), Mello e Souza (2000), Costa (1989), Brookshaw (1983), entre outros.

19 O trabalho de Chu e Wood Jr. (2008), ainda que não apresente os traços culturais como sua problemática central, realiza uma reflexão interessante sobre este assunto. Tal texto soma-se às contribuições das pesquisas de Freitas (1997), Motta (1997) e de Barros e Prates (1997). 
Já a ponderação de Martins (1997) acerca da existência de uma espécie de sincretismo burocrático-patrimonialista na administração pública brasileira, e de sua relação com a cultura organizacional, refere-se à outra possibilidade de abordagem da ambiguidade da cultura brasileira, pois contribui para a interpretação a respeito dos traços nacionais na esfera das organizações, destacando outro registro. Segundo este, tais traços funcionariam como obstáculos à efetivação da modernização institucional do país. Dessa forma, o autor define o sincretismo burocrático-patrimonialista enquanto um processo caracterizado por uma:

[...] modernização dissociativa, onde a construção burocrática [...] [foi] tendencialmente obstaculizada pela política. A consequência é que deste processo se obt[eve] uma modernização incompleta, ressabiada, descolada e ressentida da política (MARTINS, 1997, p. 181).

Por sua vez, o trabalho de Aidar e Alves nos proporciona uma análise instigante sobre a cultura organizacional ao destacar que no interior "[...] de uma organização, os significados somente são partilhados dentro de cada grupo constituinte, variando conforme os níveis hierárquicos" (AIDAR; ALVES, 1997, p. 207-208). Esta apreciação nos permite entender as dificuldades e os desafios que envolvem resolver o problema da existência de barreiras na comunicação interna das organizações, sejam estas empresas ou outras.

Semelhante problema fica evidenciado quando os dirigentes (de uma organização qualquer) procuram difundir novos conceitos e/ou novas filosofias administrativas e não encontram interlocução com os subordinados, devido às diferenças existentes entre seus repertórios culturais. Tais diferenças seriam as responsáveis por dificultar e, em alguns casos, por impedir uma comunicação organizacional satisfatória. Decorre desta situação, a necessidade de se repensar a relação entre os conteúdos das mensagens e os seus veículos de transmissão no espaço organizacional.

Para uma abordagem mais adequada deste espaço, faz-se necessário explicitar a noção de cultura organizacional que, até então, esteve subjacente ao longo deste tópico do artigo. Visando satisfazer a esta demanda, recorremos aos trabalhos de Fleury, Shinyashiki e Stevanato (1997) e de Barbosa (2002, 1999, 1996). De acordo com estes 
autores, a concepção de cultura organizacional que se tornou clássica foi elaborada por Edgar Schein, que assim a definiu:

[...] conjunto de pressupostos básicos que um grupo inventou, descobriu ou desenvolveu ao aprender como lidar com os problemas de adaptação externa e integração interna e que funcionaram bem o suficiente para serem considerados válidos e ensinados a novos membros como a forma correta de perceber, pensar e sentir em relação a esses problemas (SCHEIN, 1989 apud FLEURY, SHINYASHIKI, STEVANATO, 1997, p. 275).

Schein (1989) estabeleceu três níveis distintos mediante os quais seria possível apreender a cultura organizacional: 1) os artefatos visíveis, isto é, a estrutura da organização (sua distribuição e quantidade de cargos) e os comportamentos das pessoas, os quais são de difícil interpretação e de fácil reconhecimento; 2) os valores, cuja adversidade se encontra na dificuldade de discernir entre os de fato em uso e os aparentes, e 3) os pressupostos básicos, ou seja, os aspectos inconscientes que determinam a forma de pensar, agir e sentir dos membros do grupo. Este terceiro item seria o nível principal à proporção que atua como base para os outros dois.

Além dos referidos níveis para entender a cultura organizacional, a obra de Schein (1989) destacou duas características importantes no conceito: “[...] a primeira é a necessidade de pensar cultura relacionada a uma unidade social e a segunda que há necessidade de estabilidade do grupo durante algum tempo" (FLEURY, SHINYASHIKI, STEVANATO, 1997, p. 275). Dessa maneira, a cultura organizacional seria a responsável por garantir a existência e a permanência da organização à medida que ela reiteraria no interior desta "a forma correta" de perceber, pensar e sentir em relação a seus problemas e soluções. Ao transpormos tais características para a cultura brasileira, encontramos apoio no pensamento de Azevedo (1971), pois, para este autor, a responsabilidade de manter a coesão da sociedade no território ao longo do tempo pertence a cultura.

Já ao mencionarmos a dimensão metodológica das pesquisas a respeito da cultura organizacional, vale destacar que há uma concorrência entre os partidários do método qualitativo e os do quantitativo. A maioria dos pesquisadores que utiliza o método qualitativo é irredutível em sua afirmação de que as culturas são únicas, 
enquanto a maioria dos que mobiliza o quantitativo defende que existem aspectos generalizáveis na cultura organizacional (FLEURY, SHINYASHIKI, STEVANATO, 1997). Esta disputa metodológica nos parece inócua, pois o fato de cada organização apresentar uma cultura única não exclui a possibilidade da existência de aspectos generalizáveis na mesma.

Assim, apontamos como pertinente a seguinte afirmação: “[...] a coerência entre a concepção do objeto a ser estudado e a abordagem metodológica a ser adotada [consiste no] [...] aspecto que deve prevalecer sobre eventuais interesses circunstanciais" (FLEURY, SHINYASHIKI, STEVANATO, 1997, p. 286). Neste sentido, sugerimos como um caminho frutífero para as investigações nas diferentes áreas do conhecimento, a combinação de diferentes métodos, pois este procedimento permite que a fraqueza de um método possa ser compensada pela força do outro. Semelhante reflexão metodológica encontra respaldo no pensamento de Azevedo, particularmente, em suas ponderações sobre a dimensão empírico-indutiva da Sociologia. E em sua trajetória institucional, ao fomentar o desenvolvimento e a consolidação da Estatística no Brasil, seja como gestor do Instituto de Educação (IEUSP) ${ }^{20}$, nos anos de 1930 , onde fundou o Laboratório de Estatística; seja como consultor técnico junto ao IBGE, nas décadas de 1940 e 1950, seja ainda como diretor do Centro Regional de Pesquisas Educacionais de São Paulo (CRPE-SP)21, no período de 1956 a 1960.

Os principais apontamentos realizados ao longo deste tópico podem ser resumidos da seguinte maneira: 1) o conceito de cultura brasileira de Azevedo (1971) compreende uma artesania interessante para explicar o funcionamento da cultura organizacional no país; 2) a estrutura escravocrata, que marcou a história do Brasil até o final do século XIX, proporcionou que as desigualdades social e simbólica se tornassem características centrais da sociedade brasileira; 3) o quadro de desigualdade social no Brasil permitiu o surgimento do alto índice de distância de poder entre os diferentes grupos sociais, e tem assegurado sua permanência até a segunda década do século XXI; 4) os traços culturais brasileiros se fazem sentir nas organizações por intermédio da

\footnotetext{
20 Ver a respeito: EVANGELISTA, O. A formação de professores em nível universitário: o Instituto de Educação da Universidade de São Paulo (1934-1938). São Paulo, 1997. Tese (Doutorado em Educação) Pontifícia Universidade Católica de São Paulo.

${ }^{21}$ Consultar a respeito: FERREIRA, M. S. O Centro Regional de Pesquisas Educacionais de São Paulo (19561961). São Paulo, 2001. Dissertação (Mestrado em Educação) - Universidade de São Paulo.
} 
cultura organizacional, compondo parte do inconsciente de cada ator social no processo de construção do que é ser brasileiro, e 5) cada organização apresenta uma cultura única, mas isso não exclui a possibilidade de existência de aspectos generalizáveis na mesma.

\section{Teorias organizacionais e cultura brasileira}

De forma bastante sucinta, é possível assinalar que o início do século XX foi marcado pela história do surgimento das teorias organizacionais. As revoluções industriais $^{22}$ e as "revoluções sociais", representadas, especialmente, pela Revolução Francesa e pela Revolução Russa, teriam trazido em seu bojo a necessidade de humanizar o ambiente organizacional empresarial. Ou seja, de criar novas estratégias organizacionais para manter os funcionários sob controle, à medida que eles eram crescentemente explorados, e ampliar a margem de lucro dos empresários.

Nesse contexto, a humanização das organizações empresariais consistiu em uma espécie de tática, não declarada, para garantir o sucesso dos empreendimentos ao passo que possibilitava um instrumento para tentar apaziguar os conflitos, manifestos e/ou latentes nas relações capital-trabalho (CALDAS; TONELLI; LACOMBE, 2002).

A aproximação entre as investigações da escola de Administração Científica e os estudos realizados pela Sociologia e Psicologia, nas primeiras décadas do século XX, indicou um aporte diferente para a proposta de humanizar as organizações empresariais. Tal contribuição contemplou entender a satisfação como um elemento definidor do comportamento das pessoas. Esta sugestão foi aprofundada pelos expoentes da Psicologia Humanista que, a partir da obra de Abraham Maslow ${ }^{23}$,

\footnotetext{
${ }^{22}$ Ocorridas na Inglaterra, no século XVIII, e nos Estados Unidos, no século XIX, e difundidas para outros países em ritmos distintos.

${ }^{23}$ Abraham Maslow (1908-1970) foi um psicólogo norte-americano considerado uma referência na Psicologia Humanista, ficou conhecido pela teoria da hierarquia das necessidades humanas, que aparece sistematizada em seu livro intitulado: Motivation and personality, de 1954. Para este autor, as necessidades humanas se encontram divididas em cinco tipos (a saber: autorrealização; estima; sociais; segurança e fisiológicas), que se manifestam em graus distintos de importância onde as fisiológicas são as necessidades iniciais e as de realização pessoal são as finais. Cada necessidade humana influencia na motivação e na realização do indivíduo o que faz com que este prossiga para as outras necessidades. Essa teoria de Maslow tem influenciado o trabalho de diversos estudiosos do comportamento humano em organizações.
} 
passaram a intervir na teoria organizacional mediante a ideia de que os seres humanos seriam motivados por uma hierarquia de necessidades (MARTELLI, 2006).

Tal "teoria da motivação" acabou por contribuir para uma visão do indivíduo como um todo, ao mesmo tempo, que permitiu considerar, dentro e fora das organizações, o funcionário como um recurso valioso para as empresas. No entanto, este reconhecimento não ultrapassou o limite de não problematizar o crescimento da exploração da mão-de-obra nas relações capital-trabalho. Essas concepções, sobre o indivíduo como um todo e o valor do funcionário, serviram para embasar o que foi considerado como gestão de recursos humanos.

O funcionário, nesta visão psicologizante, passou a ser concebido como reativo e não mais como passivo. De qualquer modo, a característica que se destacou, seja na escola de Administração Científica, seja na de Relações Humanas, foi o posicionamento de seus teóricos de ignorar o problema do conflito no interior das organizações empresariais.

Diferentemente dos representantes das escolas de Administração Científica e de Relações Humanas, os behavioristas teriam admitido a existência de certa dose de conflito entre as necessidades dos indivíduos e as das organizações. Para estes estudiosos, tal problema poderia ser solucionado, com certa facilidade, mediante uma posição favorável das empresas diante das necessidades dos indivíduos. Já para um intelectual como Motta (1985), esta interpretação dos behavioristas compreendeu apenas uma forma diferente de fazer o mesmo, isto é, outra maneira de ignorar a existência de conflitos.

Ao deslocar a dimensão de conflito, as teorias organizacionais construídas pelos pensadores dessas escolas, e pelos behavioristas, estabeleceram uma ideia de funcionário como um ser universal abstrato, desconsiderando suas diferenças étnicas, religiosas, econômicas, políticas etc. Uma parte da explicação sobre as razões que teriam influenciado tais teorias a ignorar as diferenças e os conflitos, fora e no universo organizacional, pode ser encontrada nos contextos histórico, político e discursivo de suas produções.

Sobretudo nas três primeiras décadas do século XX, diversos países se preocuparam com o tema da nação, sua unidade e seu progresso, o que implicou na ausência de espaços para o reconhecimento da heterogeneidade, a qual resultasse em 
uma visão acerca do trabalhador como um ser concreto. No Brasil, esse processo se tornou perceptível a partir da década de 1920, quando diferentes grupos dirigentes, como governos e empresários, buscaram inventar, tanto no discurso quanto na prática, uma nação moderna e coesa. Entendemos que esta postura teria influenciado uma parcela da intelectualidade brasileira, marcada por espectros políticos e matrizes teóricas distintos, a elaborar explicações sobre os problemas do país, nas quais a dimensão de conflito permanecesse latente.

Como um contraponto às concepções que procuraram enfatizar a harmonia e a cooperação, os teóricos estruturalistas passaram a trabalhar com as categorias de análise que explicitavam o conflito e a concorrência entre os diversos grupos sociais, especialmente, a partir dos anos de 1950. Merton (1968) e Etzioni (1984) são exemplos de pesquisadores estrangeiros que afirmaram o conflito e a competição como dimensões estruturais do modelo capitalista. Isto é, que reconheceram o conflito como algo inerente às relações sociais, sobretudo, às relações produtivas.

No Brasil, alguns teóricos da "escola paulista de sociologia"24, e outros intelectuais, realizaram análises com abordagens semelhantes às de Merton (1968) e Etzioni (1984). Esses teóricos contribuíram interna e externamente para expandir e legitimar o emprego do conceito de classes sociais, principalmente, após a década de 1960. Dessa maneira, o referencial marxista passou a ser mobilizado por parte dos sociólogos brasileiros para interpretar as mudanças e seus entraves nas relações entre os países desenvolvidos e subdesenvolvidos, bem como no interior de tais países, inclusive, mediante o advento da Terceira Revolução Industrial.

Iniciada nos anos de 1970, a Terceira Revolução possibilitou uma nova etapa no processo de globalização: as contradições do capitalismo foram difundidas, ampliadas e atualizadas. De um lado, houve um aumento expressivo da produção nos diversos setores econômicos, em virtude do emprego crescente da tecnologia e de seus constantes e rápidos avanços. De outro, manteve-se a estratificação entre os países a partir do reconhecimento da presença, ou não, de desenvolvimento em seu interior. Apesar da maior e melhor comunicação entre os distintos territórios, que foi

\footnotetext{
${ }^{24}$ Esta "escola" tem na figura de Florestan Fernandes seu principal expoente. Sobre a referida "escola" consultar: ARRUDA, Maria Arminda do Nascimento. Metrópole e cultura: São Paulo no meio século XX. Bauru-SP: Edusc, 2001.
} 
possibilitada pela tecnologia, conservaram-se explícitas as desigualdades social e simbólica.

Ao lado das lutas políticas por ampliação e efetivação dos direitos (em particular, dos direitos sociais) desenvolveu-se, nas duas últimas décadas do século XX, um processo crescente e generalizado de fragilização das referências sociais, religiosas, políticas, culturais, entre outras. O que implicou na elevação, sem precedente, do sentimento de insegurança dos indivíduos com relação ao presente e mais ainda com relação ao futuro (BAUMAN, 2004).

A ideia de crise parece ter se tornado o baluarte dos atores sociais em distintos países, a despeito de sua posição no sistema capitalista mundial/global, isto é, de serem classificados como desenvolvidos ou subdesenvolvidos. A crise e a insegurança se converteram em importantes consequências da modernidade para vários agrupamentos humanos no Ocidente (GIDDENS, 1991). Passamos a viver, como argumentou Giddens (1991) na última década do século XX, em uma época marcada pela desorientação, pela sensação de que não compreendemos plenamente os eventos sociais, e mais, que perdemos o controle.

O início do século XXI tem se caracterizado, no Brasil e em outros lugares, pela intensificação da sensação de incerteza e de angústia. Nesse sentido, é possível apontar que a modernidade vem transformando as relações sociais e a percepção dos indivíduos e coletividades sobre a segurança e a confiança. Sendo a modernidade "inerentemente globalizante", para usarmos as palavras de Giddens (1991), ela nos impôs a necessidade de entendermos a globalização. Esta, de forma geral, comporta um processo caracterizado por transformações contraditórias e universalizantes que são responsáveis por reconfigurarem tanto a tradição quanto a própria modernidade.

No âmbito organizacional, parte dos dirigentes e dos funcionários reage à incerteza e à desorientação, nos termos expostos por Bauman (2004) e Giddens (1991), agarrando-se aos atores e às ideias que possam se apresentar, ao menos momentaneamente, como alicerces seguros para orientarem a construção e manutenção de suas identidades; mas que, além disso, possam satisfazer à condição de portadores do estandarte da modernidade. 
Inicia-se assim, no interior das organizações, um processo de reprodução das referidas ideias e de submissão aos líderes ${ }^{25}$, que forem reconhecidos como capazes de efetivá-las. É este o momento em que “[...] as organizações modernas se vêem [no sentido da imagem que criam e recriam para si e para os outros] como as novas catedrais" (M. FREITAS, 1997, p. 298).

De acordo com M. Freitas (1997), as organizações assim como a sociedade possuem um conjunto de ideais que as orientam. Partindo desta constatação, a autora expõe como problemático a utilização da cultura organizacional para induzir parte do quadro funcional, de uma determinada organização, a enxergá-la enquanto uma alternativa para satisfazer seus anseios pessoais por segurança e identidade.

Ainda para M. Freitas (1997), as organizações, ao colaborarem para a difusão e consolidação da ideia do "sempre mais, sempre mais" como motor da existência dos indivíduos, transformam a cultura em um perverso instrumento de controle. Uma vez que ela passa a estimular desejos e expectativas que são fontes de novos desejos e de novas expectativas, os quais não encontrarão meios de serem satisfeitos. Já a cultura organizacional se converte em um instrumento político, posto que as organizações passam a utilizá-la para reduzir o conceito de identidade, tornando a si próprias uma fonte de reconhecimento para seus membros.

Diferentemente do repertório teórico que continua defendendo o uso dos conceitos de modernização e transformação para explicar as organizações latinoamericanas no contexto da globalização, Calás e Arias (1997) expressam a necessidade de deslocá-los e de assumir em seu lugar o de hibridização. De acordo com estas autoras, o conceito de hibridização consiste em um "[...] outro discurso possível (e bastante provisório), localizado especificamente no contexto do pós-modernismo latinoamericano, para a teorização sobre as organizações latino-americanas" (CALÁS, ARIAS, 1997, p. 320). O referido contexto seria caracterizado pela substituição dos modelos explicativos de modernização e dependência pelas novas preocupações com a identidade, a subjetividade e a heterogeneidade cultural.

\footnotetext{
${ }^{25}$ Há vários caminhos alternativos ao da submissão aos líderes, apesar de reconhecermos a relevância de uma abordagem que contemple tais caminhos a mesma não será satisfeita neste artigo. Uma obra interessante para tal abordagem é NOGUEIRA, Marco Aurélio. Um Estado para a sociedade civil. Temas éticos e políticos da gestão democrática. São Paulo: Cortez, 2004.
} 
Essa definição de hibridização de Calás e Arias (1997) nos permite dialogar tanto com os teóricos da cultura brasileira (e seus traços), quanto com os estudiosos das teorias organizacionais, no seguinte registro: a cultura brasileira passa a ser considerada uma espécie de síntese provisória marcada por traços paradoxais, e as culturas organizacionais como expressões destes paradoxos. Desse modo, o conceito de hibridização nos possibilita uma espécie de chave explicativa para a afirmação e negação da transição dos "antigos" modelos para as "novas" preocupações. Ou seja, favorece uma maneira criativa de estruturar e compreender os laços entre o moderno e o tradicional, o estrangeiro e o nacional/local, ao mesmo tempo que passa a ser desafiada por eles.

Calás e Arias (1997, p. 323) compreendem que "[...] o conceito de hibridização não tem a durabilidade de uma identidade fixa". No entanto, elas enxergam sua potência heurística ao assegurar o desenvolvimento de uma interpretação flexível, transitória, apenas conjunturalmente aceita. Segundo estas autoras, o grande desafio para os estudiosos das teorias organizacionais é modificar os limites disciplinares que eles próprios se colocaram no processo de definição e de aplicação de suas abordagens teórico-metodológicas. Assim, ao longo de seu livro, elas buscam provocar e convidar seus leitores a ousar, ou seja, a se aventurarem a pensar e a agir de modo diferente frente ao objeto do conhecimento.

Ao voltarmos nosso olhar para o conceito de cultura brasileira na obra de Azevedo, e para sua influência sobre a definição de cultura organizacional, ao longo deste tópico, ousamos problematizar a relação entre ambos, entendendo estar contribuindo para reiterar a relevância de um repertório cultural flexível, capaz de elucidar parte das interpretações e dos problemas vivenciados pela sociedade e pelas organizações no Brasil.

\section{Considerações finais}

A concepção de cultura brasileira de Fernando de Azevedo, considerada paradoxal aos olhos de alguns intérpretes, lhe possibilitou responder à demanda do governo varguista por uma identidade nacional, nas décadas de 1930 e 1940, fornecendo diretrizes para compreendermos os comportamentos dos indivíduos e dos 
grupos no interior das organizações, para além do período mencionado. Na visão deste autor, a cultura era responsável pela coesão da sociedade ao permitir explicar o que proporciona a mudança e a continuidade do organismo social.

Ao constatar que as ideias, os desejos, os valores, os sentimentos e os interesses dos indivíduos agem sobre seus comportamentos no meio organizacional, inclusive que eles colaboram para moldar este último e vice-versa, a cultura converteuse em uma espécie de chave para explicar as ações dos diferentes atores no interior das organizações. E, com isso, para tentar coordenar tais atos sem recorrer a quaisquer mecanismos explícitos de coerção. Desse modo, o conceito de cultura proporcionou uma contribuição ímpar para pensar a construção de distintos modelos de gestão de pessoas.

Ademais, o reconhecimento da existência de traços culturais e da indissociabilidade das experiências, dos interesses, dos valores dos indivíduos sugere que o sucesso de um modelo de gestão de pessoas está diretamente relacionado à consideração dos traços culturais de cada organização (VILLARDI; FERRAZ; DUBEUX, 2011).

Nas imbricações entre os conceitos de cultura brasileira e de cultura organizacional foi possível perceber que a concepção de cultura de Azevedo orientou, de forma implícita ou explícita, parte dos teóricos organizacionais, a exemplo de Barros e Prates (1997), Motta (1997), Freitas (1997) e Martins (1997), que se preocupou em demonstrar como as culturas nacionais influenciam nos estilos administrativos. Neste caminho, tais autores desenvolveram algumas reflexões acerca das possibilidades e limites da formação histórica, cultural, social e econômica do país, relacionando-as com os traços culturais brasileiros, que foram e são entendidos como variáveis importantes para explicação do meio socioinstitucional. 


\section{Referências}

AIDAR, Marcelo Marinho; ALVES, Mário Aquino. Comunicação de massa nas organizações brasileiras: explorando o uso de histórias em quadrinhos, literatura de cordel e outros recursos populares de linguagem nas empresas brasileiras. In: MOTTA, Fernando Claudio Prestes; CALDAS, Miguel Pinto. (Orgs.). Cultura organizacional $e$ cultura brasileira. São Paulo: Atlas, 1997. p. 203-220.

AZEVEDO, Fernando de. A cidade e o campo na civilização industrial: e outros estudos. São Paulo: Melhoramentos, 1962.

AZEVEDO, Fernando de. A cultura brasileira. São Paulo: Melhoramentos; EDUSP, 1971.

BARBOSA, Lívia. Cultura administrativa: uma nova perspectiva das relações entre antropologia e administração. RAE - Revista de Administração de Empresas, v. 36, n. 4, p. 6-19, out./nov./dez. 1996.

BARBOSA, Lívia. Cultura e empresas. Rio de Janeiro: Jorge Zahar, 2002.

BARBOSA, Lívia. Igualdade e meritocracia, a ética do desempenho nas sociedades modernas. Rio de Janeiro: Fundação Getúlio Vargas, 1999.

BARROS, Betânia Tanure de; PRATES, Marco Aurélio Spyer. O estilo brasileiro de administrar: sumário de um modelo de ação cultural brasileiro com base na gestão empresarial. In: MOTTA, Fernando Claudio Prestes; CALDAS, Miguel Pinto. (Orgs.). Cultura organizacional e cultura brasileira. São Paulo: Atlas, 1997. p. 55-70.

BAUMAN, Zygmunt. Amor líquido: sobre a fragilidade dos laços humanos. Rio de Janeiro: Jorge Zahar, 2004.

BION, Wilfred Ruprecht. Experiências com grupos: os fundamentos da psicoterapia de grupos. Rio de Janeiro/São Paulo: Imago/Edusp, 1975.

BOSI, Alfredo. (Org.). Cultura brasileira: temas e situações. São Paulo: Ática, 1999.

BROOKSHAW, David. Raça \& cor na literatura brasileira. Porto Alegre: Mercado Aberto, 1983.

CALÁS, Marta B.; ARIAS, Maria Eugênia. Compreendendo as organizações latinoamericanas: transformação ou hibridização? In: MOTTA, Fernando Claudio Prestes; CALDAS, Miguel Pinto. (Orgs.). Cultura organizacional e cultura brasileira. São Paulo: Atlas, 1997. p. 316-325.

CALDAS, Miguel Pinto; TONELLI, Maria José; LACOMBE, Beatriz. Desenvolvimento histórico do RH no Brasil e no mundo. Manual de gestão de pessoas e equipes. V. I. São Paulo: Gente, 2002.

CHU, Rebeca Alves; WOOD JR., Tomaz. Cultura organizacional brasileira pósglobalização: global ou local? Revista de Administração Pública - RAP, Rio de Janeiro, $\mathrm{n}$. 42, v. 5, p. 969-991, set./out., 2008.

COSTA, Jurandir Freire. Ordem médica e norma familiar. Rio de Janeiro: Graal, 1989. 
DUTRA, Eliana Regina de Freitas. A nação nos livros: a biblioteca ideal na Coleção Brasiliana. In: DUTRA, Eliana Regina de Freitas; MOLLIER, Jean-Yves. (Orgs.). Política, nação e edição. O lugar dos Impressos na Construção da Vida Política. Brasil, Europa e Américas. Séculos XVII-XX. 1 ed. São Paulo: Annablume, 2006. p. 299-314.

ETZIONI, Amitai. Organizações modernas. São Paulo: Pioneira, 1984.

FLEURY, Maria Tereza Leme; SHINYASHIKI, Gilberto Tadeu; STEVANATO, Luiz Arnaldo. Arqueologia teórica e dilemas metodológicos dos estudos sobre cultura organizacional. In: MOTTA, Fernando Claudio Prestes; CALDAS, Miguel Pinto. (Orgs.). Cultura organizacional e cultura brasileira. São Paulo: Atlas, 1997. p. 273-292.

FREITAS, Alexandre Borges de. Traços brasileiros para uma análise organizacional. In: MOTTA, Fernando Claudio Prestes; CALDAS, Miguel Pinto. (Orgs.). Cultura organizacional e cultura brasileira. São Paulo: Atlas, 1997. p. 38-54.

FREITAS, Maria Esther de. Cultura organizacional: o doce controle no clube dos raros. In: MOTTA, Fernando Claudio Prestes; CALDAS, Miguel Pinto. (Orgs.). Cultura organizacional e cultura brasileira. São Paulo: Atlas, 1997. p. 293-304.

FREYRE, Gilberto. Casa grande e senzala: introdução à história da sociedade patriarcal no Brasil. Rio de Janeiro: Record, 2000.

GIDDENS, Anthony. As consequências da modernidade. São Paulo: UNESP, 1991. GEERTZ, Clifford. A interpretação das culturas. Rio de Janeiro: LTC, 1989.

HOLANDA, Sergio Buarque de. Raízes do Brasil. Rio de Janeiro: José Olympio, 1989.

LESSER, Jeffrey. A negociação da identidade nacional: Imigrantes, minorias e a luta pela etnicidade no Brasil. São Paulo: UNESP, 2001.

DAMATTA, Roberto. Canaviais, malandros e heróis. Rio de Janeiro: Zahar, 1983.

DAMATTA, Roberto. A casa e a rua. São Paulo: Brasiliense, 1985.

DAMATTA, Roberto. O que o Brasil, Brasil? Rio de Janeiro: Rocco, 1986.

MARTELLI, Carla Gandini Giani. Autoajuda e gestão de negócios: uma parceria de sucesso. Rio de Janeiro: Azougue Editorial, 2006.

MARTINS, Humberto Falcão. A ética do patrimonialismo e a modernização da administração pública brasileira. In: MOTTA, Fernando Claudio Prestes; CALDAS, Miguel Pinto. (Orgs.). Cultura organizacional e cultura brasileira. São Paulo: Atlas, 1997. p.171183.

MELLO e SOUZA, Antonio Candido. Literatura e sociedade. São Paulo: T. A. Queiroz; Publifolha, 2000.

MERTON, Robert K. Sociologia: teoria e estrutura. São Paulo: Editora Mestre Jou, 1968.

MORTARA, Giorgio. Os aspectos internacionais do recenseamento. Revista Brasileira de Estatística - IBGE. Rio de Janeiro, Ano I, no. 3, p. 421-431, jul./set., 1940.

MOTA, Carlos Guilherme. Ideologia da cultura brasileira: Pontos de partida para uma revisão histórica. São Paulo: Ática, 2002. 
MOTTA, Fernando Claudio Prestes. Cultura e organizações no Brasil. In: MOTTA, Fernando Claudio Prestes; CALDAS, Miguel Pinto. (Orgs.). Cultura organizacional e cultura brasileira. São Paulo: Atlas, 1997. p. 25-37.

MOTTA, Fernando Claudio Prestes. Teoria geral de administração. São Paulo: Pioneira, 1985.

NASCIMENTO, Alessandra Santos. A construção da nação arco-íris: problematizando o quesito raça/cor (1936-1960). Araraquara-SP, 2005. Dissertação (Mestrado em Sociologia) - Universidade Estadual Paulista Júlio de Mesquita Filho.

NASCIMENTO, Alessandra Santos. Fernando de Azevedo - Coleção Clássicos \& Contemporâneos. 1. ed. V. 1. Penápolis: FUNEPE, 2018.

NASCIMENTO, Alessandra Santos. Fernando de Azevedo: dilemas na institucionalização da Sociologia no Brasil. 1. ed. São Paulo: Cultura Acadêmica, 2012.

ORTIZ, Renato. Cultura brasileira e identidade nacional. São Paulo: Brasiliense, 2003.

REVISTA DE ECONOMIA E ESTATÍSTICA. Rio de Janeiro: INE, Ano II, n. 1, p. 55-63, 1937. Seção Notícias sobre o desenvolvimento da Estatística.

SCHEIN, Edgar H. Organizational culture and leadership. San Francisco: JosseyBass, 1989.

SCHEIN, Edgar H. Organizationat psychology. Englewood Cliffs, N. J.: PrenticeHall, 1965.

SCHNEIDER, Jens. Discursos simbólicos e símbolos discursivos: Sobre a etnografia da Identidade Nacional. MANA, Rio de Janeiro, v. 10 (1), p. 97-129, 2004.

SODRÉ, Muniz. A verdade seduzida: por um conceito de cultura no Brasil. Rio de Janeiro: Francisco Alves, 1988.

TOLEDO, Maria Rita de Almeida. Fernando de Azevedo e a Cultura Brasileira: ou as aventuras e desventuras do criador e da criatura. São Paulo, 1995. Dissertação (Mestrado em Educação) - Pontifícia Universidade Católica de São Paulo.

VILLARDI, Beatriz Quiroz; FERRAZ, Viviane Narducci; DUBEUX, Veranise Jacubowski Correia. Uma metodologia para diagnóstico de clima organizacional: integrando motivos sociais e cultura brasileira com fatores do ambiente de trabalho do Poder Judiciário. Revista de Administração Pública - RAP, Rio de Janeiro, v. 45 (2), p. 303-329, mar./abr., 2011.

WOOD JR., Tomaz. Terra em transe: liderança em Eldorado. In: MOTTA, Fernando Claudio Prestes; CALDAS, Miguel Pinto. (Orgs.). Cultura organizacional e cultura brasileira. São Paulo: Atlas, 1997. p. 143-156. 